\section{ОСОБЕННОСТИ ПРАВОВОГО РЕГУЛИРОВАНИЯ ДОГОВОРА ВОДОПОЛЬЗОВАНИЯ}

\section{Аннотация:}

В статье рассматриваются вопросы совершенствования правовой модели договора водопользования в целях обеспечения баланса публичных и частных интересов в правовом регулировании данных отношений. Предлагается внести в водное законодательство изменения, направленные на обеспечение экологической обоснованности и экономической эффективности договорного регулирования водопользования. Определяя отраслевую принадлежность рассматриваемого договора, автор отмечает признаки гражданско-правового договора смешанного типа. Признание договора водопользования видом гражданско-правовых договоров позволяет распространить на данные отношения основополагающие принципы гражданского права, включая принципы равенства участников правоотношений, добросовестности, частной инициативы. В работе анализируются особенности реализации принципа добросовестности в сфере договорного регулирования водопользования. Основываясь на правовой характеристике особенностей правового режима водных объектов в качестве объектов имущественных отношений, автор подчеркивает необходимость установления специфических критериев оценки добросовестного поведения участников договора водопользования, относя к данным критериям проявление должной заботливости в вопросе охраны водного объекта.

Ключевые слова:

договор, водный объект, водопользование, законодательство, кодекс, право, экологическое право.

\section{THE ASPECTS OF LEGAL REGULATION OF WATER USE AGREEMENT}

\begin{abstract}
Summary:
The study discusses the issues of improving the legal water use agreement model in order to keep a balance between the public and private interests in the legal regulation of these relationships. It is proposed to amend the Russian water legislation to ensure the environmental feasibility and economic viability of water use agreements. The author reveals that an agreement under consideration can be regarded as a mixed-type civil contract. It substantiates the fact that the fundamental principles of civil law, including the principles of equality of the parties to legal relationships, good faith, and private initiatives, can apply to water use agreement. The aspects of the principle of good faith are analyzed in the context of water use regulation by treaty. Based on the legal characteristics of the legal regime set up in relation to water bodies as a subject of property relations, the author emphasizes the need to establish the specific criteria for assessing the good faith of the parties to water use agreements regarding due diligence in water body safety matters as such a criterion.
\end{abstract}

Keywords: agreement, water body, water use, legislation, code, law, environmental law.

Современное развитие общества сопровождается значительным усилением воздействия на окружающую среду. За последнее столетие общий объем потребления воды возрос более чем в шесть раз [1, с. 3]. Усиливаются процессы загрязнения водных объектов. Во многих случаях производственная деятельность приводит к необратимым изменениям состояния водных объектов, их истощению либо опасному загрязнению. Поскольку основным источником негативного воздействия на состояние водных объектов является производственно-хозяйственная деятельность человека, разрешение данных проблем диктует необходимость применения правовых средств регулирования водопользования и охраны водных объектов, соответствующих сложившейся в обществе системе экономических отношений.

Правовое регулирование использования водных объектов подчинено целям удовлетворения потребностей широкого круга субъектов - Российской Федерации, субъектов Российской Федерации, муниципальных образований, юридических и физических лиц при использовании водных объектов для хозяйственных целей и одновременно обеспечения охраны водных объектов как важнейшего компонента окружающей среды. Задача согласования публичных и частных интересов в рассматриваемой сфере отношений диктует необходимость развития правового института договорного регулирования водных отношений.

На основе договорного регулирования водных отношений осуществляется отраслевая конкретизация прав и обязанностей водопользователей, что предполагает разрешение вопроса об 
отраслевой принадлежности договора водопользования. Данный вопрос необходимо рассматривать с позиций соотношения признаков данного вида договоров с договорами гражданско-правового типа и публично-правовыми договорами, установления пределов гражданско-правового регулирования отношений в сфере водопользования.

Вопрос о правовой природе договоров в сфере использования и охраны водных объектов подлежит разрешению с целью выявления соотношения публичного и частного права в сфере водных отношений. Как отмечал И.А. Покровский, границы между частным и публичным правом никогда не были однозначно определенными и постоянно менялись [2, с. 11-12].

Применимость в отношении водных объектов принципов гражданско-правового договорного регулирования предполагает установление соответствия договора водопользования основным началам гражданского законодательства, которые отражены в п. 1 ст. 1 Гражданского кодекса РФ (ГК РФ) и предусматривают принципы равенства участников регулируемых гражданским законодательством отношений, неприкосновенности собственности, свободы договора, недопустимости произвольного вмешательства кого-либо в частные дела, необходимости беспрепятственного осуществления гражданских прав, обеспечения восстановления нарушенных прав, их судебной защиты. В соответствии с п. 3 названной статьи установление, осуществление и защита гражданских прав и исполнение гражданских обязанностей должны основываться на правилах добросовестности участников гражданских правоотношений.

Возрастание роли гражданского права в условиях рыночных отношений неразрывно связано с развитием гибкости правовых норм на основе использования оценочных понятий. Категория «добросовестность» оценивается в юридической науке и правоприменительной практике на основе сложившихся в обществе морально-этических представлений о «честном» поведении. Выявление и закрепление в законодательстве правовых критериев оценки добросовестного поведения противоречат логике правового регулирования данных отношений и предполагают формирование правовых представлений о данном правовом явлении на основе норм морали и нравственности. Данный подход получил признание в европейском праве и раскрыт в трудах известных ученых в области европейского гражданского права [3].

В российском праве данный принцип трактуется с фрормально-юридических позиций. Данная категория применительно к договорным отношениям используется в ст. 302 Гражданского кодекса РФ «Истребование имущества от добросовестного приобретателя». Данная статья предусматривает формально определенный правовой критерий признания лица добросовестным приобретателем. Таким критерием является отсутствие у приобретателя информации об отсутствии у контрагента правомочий на совершение сделки. Применительно к другим группам отношений (корпоративные, фринансовые) положения о добросовестности закреплены также в иных статьях ГК РФ и иных актах гражданского законодательства.

Правовая конструкция добросовестности в российском гражданском праве имеет юридически определенный характер, в отличие от правовой модели добросовестности, используемой в зарубежном праве, основанной на моральных критериях оценки честного поведения. Анализ преимуществ и недостатков российской правовой модели содержится в работах таких ученых, как И.Б. Новицкий [4, с. 81], М.Ф. Лукьяненко [5] и др. И.Б. Новицкий подчеркивал преимущества оценочных категорий в гражданском праве, отмечая их эластичность, гибкость. Иного подхода придерживаются ученые, рассматривающие оценочные категории как следствие нежелания законодателя утруждать себя мучительным поиском подходящей формулировки и попытку тем самым переложить всю ответственность на плечи судей [6, с. 105].

Исторический опыт развития русского гражданского права, а также гражданского права зарубежных стран свидетельствует о признании преимуществ гибкого регулирования имущественных отношений на основе оценочных категорий. Данный подход возобладал и в современном законодательстве. Однако сложившиеся традиции позитивного права не позволяют говорить о применении оценочного подхода в полной мере. Так, статья 302 ГК РФ отражает «интеллектуальный» аспект «добросовестного» поведения - информированность об управомоченности контрагента. При этом юридически безразличными являются такие показатели, как долженствование получать информацию, субъективная способность получать и анализировать информацию о данном факте.

Содержание принципа добросовестности принято раскрывать с позиции оценки исполнения обязанности проявлять должную заботливость о правах и интересах других участников гражданского оборота [7]. Сочетание в правовой характеристике водного объекта свойств публичного и частного блага предполагает выработку специфических критериев оценки добросовестности водопользователя как субъекта договорных отношений. Представляется важным с точки зрения целей регулирования водных отношений применение гибкого подхода к трактовке категории добросовестности, основанной на выявлении должной заботливости водопользователя к вопросам охраны водного объекта как природного блага. Необходимо формирование в судебной практике 
подхода, состоящего в оценке добросовестности участников договорных отношений в сфере водопользования с точки зрения принятия водопользователем мер, необходимых для предотвращения экологического вреда и сохранения водного объекта в процессе его использования.

В целях обеспечения природоохранной направленности договорного регулирования водных отношений законодатель применяет метод дискреции объектов, на основе которого осуществляется дифференциация договорных режимов в данной сфере с использованием различных критериев ограничения свободы усмотрения сторон при формировании договорных отношений.

Невозможность отождествления объекта договорных отношений на основе определения границ акватории водного объекта исключает применение договорного регулирования пользования поверхностными водными объектами в целях использования акватории водного объекта. При этом в законодательстве отсутствует четкое определение перечня случаев, при которых исключается заключение договора водопользования в целях предоставления акватории водного объекта в пользование. Формулировка подп. 2 п. 2 ст. 11 Водного кодекса РФ (ВК РФ) не позволяет выявить правовые признаки объекта водопользования, осуществляемого в целях использования акватории. Изменения, внесенные в данную статью федеральным законом от 26 июля 2017 г. № 208-Ф3, были направлены на уточнение перечня объектов договорных отношений в сорере водопользования. Применительно к такому виду объектов, как акватории, законодатель ограничил перечень объектов договорных отношений, указав на исключение договорного регулирования применительно к случаям, указанным в п. 3 и 4 ст. 11 ВК РФ. Однако в п. 3 названной статьи говорится о приоритете п. 2 названной статьи. Остается нерешенным вопрос о том, какой статьей руководствоваться при квалификации в качестве объекта договорных отношений акватории водного объекта. Неясно, в каком из 11 случаев, перечисленных в п. 3 ст. 11 ВК РФ, объектом водопользования является акватория водного объекта. Правовая неопределенность в данном вопросе может явиться источником нарушений, состоящих в создании в процессе оказания государственных и муниципальных услуг неравных экономических условий приобретения права водопользования для различных субъектов права.

Термин «акватория» определяется как водное пространство в пределах естественных, искусственных или условных границ (ст. 1 ВК РФ). Лингвистическое толкование термина «акватория» содержится в толковых словарях, в которых акватория определяется как «участок водной поверхности, включая акватории портов и бухт» («Современный словарь иностранных слов», 2011). Буквальное толкование правового определения названного понятия с учетом его лингвистического значения позволяет провести классификацию акваторий на естественные и искусственные. Режим естественных акваторий дифференцирован в зависимости от их территориального расположения. За пределами национальной юрисдикции прибрежных государств действуют правила, предусмотренные международными актами. По международному праву «вся акватория океанов и открытого моря, кроме относительно малой площади внутренних вод государств, открыта для хозяйственного использования бесплатно для всех государств, включая государства, не имеющие выхода к морю» [8].

Применительно к внутренним водам объект права водопользования дифференцирован. Содержание ст. 11 ВК РФ позволяет выделить следующие виды объектов: акватория водного объекта и часть береговой линии. При этом в законодательстве четко не выражены логика и основания названной дифференциации. Между тем выделение и разделение названных объектов имеет важное экономическое и экологическое значение, поскольку является основанием распределения бремени затрат, связанных с охраной водного объекта. В случае предоставления в пользование акватории водного объекта на водопользователя возлагается обязанность размещения гидротехнических сооружений, обеспечивающих инфраструктуру пользования водным объектом. Эксплуатация данных объектов связана с осуществлением особых видов воздействия на состояние водного объекта, нуждающихся в специальном правовом регулировании. Так, размещение в акватории водного объекта линейных объектов (трубопроводов и др.), если такое размещение связано с изменением дна и берегов водного объекта, осуществляется на основании решения о предоставлении водного объекта (подп. 5 п. 3 ст. 11 ВК РФ). В данном случае законодатель учитывает экологические аспекты деятельности, связанной с размещением данных объектов. Однако правовое регулирование отношений, связанных с эксплуатацией гидротехнического сооружения, законодатель необоснованно отделяет от регулирования отношений, связанных с эксплуатацией данного объекта. Пробел в законодательстве относительно оснований водопользования в целях эксплуатации гидротехнического сооружения, как представляется, может явиться источником недобросовестных действий со стороны как водопользователей, так и государственных и муниципальных органов. Данные действия могут найти выражение в использовании акватории водного объекта для эксплуатации гидротехнического сооружения без решения о предоставлении (поскольку строительство завершено) и без договора (поскольку нет определенности в вопросе, является ли объектом водопользования в данном случае акватория водного объекта). Представляется необходимым дополнить пункт 3 ст. 11 ВК РФ перечнем видов водопользования, осуществляемых в целях использования акватории водного объекта. Необходимо также внести изменения в подп. 2 п. 2 ст. 11 ВК РФ, 
изложив данный пункт в следующей редакции: «использование акватории водного объекта в целях эксплуатации расположенных в границах водного объекта линейных и иных сооружений, за исключением случаев, установленных пунктом 3 статьи 11 Водного кодекса РФ».

Водное законодательство предусматривает особенности возникновения права водопользования в порядке правопреемства в отношении прав и обязанностей, предусмотренных договором водопользования. Данные особенности следует рассмотреть в соотношении с общими положениями о правопреемстве, предусмотренными гражданским законодательством.

В соответствии с п. 1 ст. 59 ГК РФ, «передаточный акт должен содержать положения о правопреемстве по всем обязательствам реорганизованного юридического лица в отношении всех его кредиторов и должников, включая обязательства, оспариваемые сторонами, а также порядок определения правопреемства в связи с изменением вида, состава, стоимости имущества, возникновением, изменением, прекращением прав и обязанностей реорганизуемого юридического лица, которые могут произойти после даты, на которую составлен передаточный акт».

Обоснование объема правопреемства осуществляется на основе совокупности фактических обстоятельств, с которыми закон связывает возникновение и прекращение прав. Этот подход нашел отражение в правовых позициях судов [9]. Ряд судов занимают позицию о совокупном рассмотрении фактов и документов, основным из которых является разделительный баланс [10]. В постановлении Федерального арбитражного суда Западно-Сибирского округа доказательством правопреемства между юридическими лицами был признан перечень основных средств, переходящих в порядке правопреемства [11].

Обобщение судебной практики позволяет прийти к выводу, что доказательством правопреемства при реорганизации юридического лица является совокупность документов и фактических данных, включая разделительный баланс и иные доказательства, которые характеризуют направленность воли субъектов данных отношений на передачу прав юридическому лицу, образованному в результате реорганизации.

Вопрос о правовых основаниях перехода права водопользования в порядке правопреемства является спорным в правовой науке. В соответствии с п. 1 ст. 19 ВК РФ, передача прав и обязанностей по договору водопользования другому лицу осуществляется в соответствии с гражданским законодательством, а следовательно, применим порядок передачи прав в порядке правопреемства. В то же время статья 19 ВК РФ предусматривает обязательность получения согласия исполнительного органа государственной власти или органа местного самоуправления на передачу прав. Данные нормы содержат противоречие, поскольку гражданское законодательство не предусматривает разрешительный порядок передачи прав при правопреемстве.

При реорганизации юридического лица, являющегося водопользователем по договору водопользования, правопреемство приобретает некоторые особенности, обусловленные публичным режимом водопользования. В частности, при реорганизации может иметь место изменение объема прав и обязанностей водопользователя, обусловленное различиями правового статуса исходного водопользователя и правопреемника договорных обязательств. Например, юридическое лицо, осуществляющее забор воды для промышленных целей, в результате присоединения приобрело права по производству электроэнергии, что предполагает заключение договора водопользования для иных целей. Названные особенности правопреемства по договору водопользования нуждаются в исследовании с позиций соотношения положений гражданского и водного законодательства в регулировании данных отношений.

Представляется, что права водопользования при реорганизации юридического лица должны быть исключены из общей имущественной массы при правопреемстве, поскольку данные права имеют преимущественно публичный характер, в то время как в порядке правопреемства могут передаваться исключительно имущественные права, реализация которых не обусловлена особенностями статуса субъекта права.

Правовой статус лиц, осуществляющих водопользование, имеет комплексный характер и включает наряду с имущественными правами публичные обязанности, которые обусловлены статусом и профилем деятельности соответствующей организации. К таким публичным обязанностям относится соблюдение цели, вида и условий использования водного объекта или его части (подп. 2 п. 1 ст. 13 ВК РФ).

Учитывая юридическую связанность возникновения права водопользования с профилем деятельности организации, приобретающей право водопользования, передача прав по договору водопользования при реорганизации юридического лица предполагает получение согласия органа исполнительной власти или органа местного самоуправления. Представляется необходимым дополнить ст. 19 Водного кодекса РФ пунктом 5 следующего содержания: «Передача прав по договору водопользования при реорганизации возможна по соглашению сторон. Условия пользования водным объектом при реорганизации юридического лица пересмотру не подлежат». 
Введение данной нормы позволит исключить переход прав в силу закона в порядке правопреемства без учета профиля деятельности образованного юридического лица.

\section{Ссылки и примечания:}

1. Вступительное слово председателя подкомитета по водным ресурсам Комитета Государственной думы Российской Федерации по природным ресурсам, природопользованию и экологии Г.А. Карлова // Международные аспекты водного законодательства. М., 2015. 112 с.

2. Покровский И.А. Основные проблемы гражданского права. Петроград, 1917. 234 с.

3. Исследование проблемы добросовестности с точки зрения соотношения морали и права предприняла С. Коломбо. Cм.: Colombo S. Good Faith: The Law and Morality // The Denning Law Journal. 1993. No. 1. P. 23-59. См. также: Bjarup J. Ought and Reality: Hägerström's Inaugural Lecture Re-considered // Scandinavian Studies in Law / ed. by P. Wahlgren. Stockholm, 2000. Vol. 40. P. 72 ; D’Angelo A. II contratto in generale. Vol. 4: La Buona Fede. Torino, 2000. P. 156 ; Munukka J. Harmonization of Contract Law: In Search of a Solution to the Good Faith Problem // Perspectives on Jurisprudence: Essays in Honor of Jes Bjarup. Stockholm, 2005. P. 229-250 ; Uda G.M. La buona fede nell'esecuzione del contratto. Roma, 2001. P. 11.

4. Новицкий И.Б. Избранные труды по гражданскому праву : в 2 т. Т. 1. М., 2006. 459 с.

5. Лукьяненко М.Ф. Оценочные понятия гражданского права: разумность, добросовестность, существенность. М., 2010. $423 \mathrm{c}$.

6. Покровский И.А. Указ. соч. С. 105

7. Лукьяненко М.Ф. Указ. соч.

8. Комментарий к Водному кодексу Российской Федерации от 3 июня 2006 г. № 74-Ф3 / под ред. О.Л. Дубовик. М., 2011. Подгот. для системы «КонсультантПлюс».

9. При наличии доказательств, подтверждающих состоявшееся правопреемство, обстоятельство, что в ЕГРЮЛ не внесена запись о прекращении деятельности реорганизованного юридического лица, не может служить основанием для освобождения истца от исполнения обязательств, перешедших в результате правопреемства. См.: Постановление Второго арбитражного апелляционного суда от 8 авг. 2014 г. по делу № A28-603/2014. Требование: О признании права собственности на объект [Электронный ресурс]. Доступ из справ.-правовой системы «КонсультантПлюс».

10. Исходя из позиции Пятого арбитражного апелляционного суда, вывод о наличии или отсутствии правопреемства между юридическими лицами необходимо делать на основе анализа разделительного баланса и оценки его в совокупности с другими доказательствами по делу, в том числе и доказательствами наличия воли юридического лица на возникновение правопреемства другого юридического лица в отношении его прав и обязанностей. При реорганизации юридического лица применяются правила универсального правопреемства, независимо от волеизъявления участников сделки. См.: Постановление Пятого арбитражного апелляционного суда от 22 мая 2014 г. № 05АП4835/2014 по делу № А59-5340/2013 [Электронный ресурс]. Доступ из справ.-правовой системы «КонсультантПлюс».

11. Постановление ФАС ЗСО от 13 дек. 2007 г. № Ф04-7782/2007(39992-А45-9).

\section{References:}

Bjarup, J \& Wahlgren, P 2000, 'Ought and Reality: Hägerström's Inaugural Lecture Re-considered', Scandinavian Studies in Law, Stockholm, vol. 40, p. 72.

Colombo, S 1993, 'Good Faith: The Law and Morality', The Denning Law Journal, no. 1, pp. 23-59.

D'Angelo, A 2000, Il contratto in generale, vol. 4, La Buona Fede, Torino, p. 156., (in Italian).

Lukyanenko, MF 2010, Estimated concepts of civil law: intelligence, conscientiousness, materiality, Moscow, 423 p., (in Russian)

Munukka, J 2005, 'Harmonization of Contract Law: In Search of a Solution to the Good Faith Problem', Perspectives on Jurisprudence: Essays in Honor of Jes Bjarup, Stockholm, pp. 229-250.

Novitsky, IB 2006, Selected works on civil law, in 2 vols., vol. 1, Moscow, 459 p., (in Russian).

'Opening speech of G.A. Karlov, the Chairman of the Subcommittee on Water Resources of the Committee of the State Duma of the Russian Federation on Natural Resources, Nature Management and Ecology' 2015, Mezhdunarodnyye aspekty vodnogo zakonodatel'stva, Moscow, 112 p., (in Russian).

Pokrovsky, IA 1917, The main challenges of civil law, Petrograd, 234 p., (in Russian).

Uda, GM 2001, La buona fede nell'esecuzione del contratto, Roma, p. 11, (in Italian). 